\title{
Microstructural Anomalies in Hot-Isostatic Pressed U-10 wt. \% Mo Fuel Plates with Zr Diffusion Barrier
}

\author{
Y. Park, ${ }^{\mathrm{a}}$ N. Eriksson, ${ }^{\mathrm{a}}$ D. D. Keiser, Jr., ${ }^{\mathrm{b}}$ J.F. Jue, ${ }^{\mathrm{b}}$ B. Rabin, ${ }^{\mathrm{b}}$ G. Moore, ${ }^{\mathrm{b}}$ Y. H. Sohn ${ }^{\mathrm{a},{ }^{*}}$ \\ ${ }^{a}$ Advanced Materials Processing and Analysis Center \\ Department of Materials Science and Engineering \\ University of Central Florida, Orlando, FL 32816, USA \\ ${ }^{\mathrm{b}}$ Idaho National Laboratory \\ PO Box 1625, Idaho Falls, ID 83401, USA
}

*Corresponding Author: $\quad$ Yongho Sohn, Ph.D., Professor

Voice: (407) 882-1181; Fax: (407) 882-1501

Email: Yongho.Sohn@ucf.edu 


\begin{abstract}
Microstructural anomalies in the co-rolled-and-HIP'ed U-10 wt.\% Mo (U10Mo) metallic fuel plate with $\mathrm{Zr}$ diffusion barrier assembly were examined as a function of HIP temperature (from 520 to $580^{\circ} \mathrm{C}$ ) and duration $(45,60,90,180$ and 345 minutes) by scanning and transmission electron microscopy. The anomalies observed in this study are carbide/oxide inclusions within the U10Mo fuel alloy, and regions of limited interaction between the U10Mo alloy and $\mathrm{Zr}$ barrier, frequently associated with carbide/oxide inclusions. In the U10Mo alloy, the cF8, Fm3m (225) UC phase $\left(\mathrm{a}=4.955 \AA\right.$ ) and $\mathrm{cF} 12, \mathrm{Fm} 3 \mathrm{~m}(225) \mathrm{UO}_{2}$ phase $(\mathrm{a}=5.467 \AA)$ were observed through out the U10Mo alloy with an approximate volume percent of 0.5 to 1.8 . The volume percent of the $\mathrm{UC}-\mathrm{UO}_{2}$ inclusions within the U10Mo alloy did not change as functions of HIP temperature and time. These inclusions phases, located near the surface of the U10Mo alloy, were frequently observed to impede the development of interdiffusion and reaction between the U10Mo alloy and $\mathrm{Zr}$ diffusion barrier. The regions of limited interaction between the U10Mo and $\mathrm{Zr}$ barrier decreased with an increase in HIP temperature, however no noticeable trend was observed with an increase in HIP duration at constant temperature of $560^{\circ} \mathrm{C}$.
\end{abstract}

Keywords: Uranium alloy, Zirconium, Microstructure, Transmission electron microscopy 


\section{Introduction}

U-Mo alloy, in the metastable $\gamma$ phase, is being considered as the fuel for Global Threat Reduction Initiative (GTRI) program with an objective of developing low-enriched uranium (LEU) fuel to replace high-enriched uranium (HEU) fuel in research and test reactors [1-5]. For GTRI, two types of U-Mo fuels systems, dispersion and monolithic designs, are being developed to increase the U density in LEU fuels. Typically, the dispersion fuel of U-7 wt.\% Mo with Al matrix has an Uranium loading of $8 \mathrm{~g} / \mathrm{cm}^{3}$ in Al-alloy matrix [6]. During irradiation, development of fission gas bubbles [7,8] and metallurgical reaction [7-15] has been reported. For higher Uranium loading, up to $15.6 \mathrm{~g} / \mathrm{cm}^{3}$, monolithic fuel system with U-10 wt.\% Mo, which require a $\mathrm{Zr}$ diffusion barrier to minimize the adverse metallurgical reaction between fuel alloy and Al-alloy cladding is being considered [16-19]. Robinson et al. [20] reported results of tests and qualifications for monolithic fuel plates to find an optimized fabrication process. The U10Mo alloy was recommended as the optimal fuel because of low swelling tendency, excellent co-rolling properties with $\mathrm{Zr}$ laminate, and good stability of $\gamma-\mathrm{U}$ at high temperature.

Previous investigations have reported microstructural development in monolithic fuel that consists of U10Mo fuel alloy, Zr diffusion barrier and AA6061 cladding [16,21]. The fuel system is fabricated by sequential process of co-rolling $\left(\sim 650^{\circ} \mathrm{C}\right)$ and hot-isostatic press $\left(\sim 520^{\circ}\right.$ to $580^{\circ} \mathrm{C}$ ) as schematically illustrated in Figure 1. Perez et al. [16] identified several phases, such as $\mathrm{UZr}_{2}, \gamma-\mathrm{U}(\mathrm{Zr}), \mathrm{Zr}$ and $\mathrm{Mo}_{2} \mathrm{Zr}$, associated with interaction between the $\mathrm{U} 10 \mathrm{Mo}$ and $\mathrm{Zr}$ after the co-rolling and HIP process. Park et al. [21] further examined phase constituents and microstructure changes as function of temperature (520, 540, 560 and $580^{\circ} \mathrm{C}$ for 90 minutes) and duration $\left(45 \sim 345\right.$ minutes at $560^{\circ} \mathrm{C}$ ) of HIP during fabrication. Between the U10Mo and $\mathrm{Zr}$ barrier, the interaction zone mainly consist of $\alpha-\mathrm{U}, \mathrm{Mo}_{2} \mathrm{Zr}$ and $\mathrm{UZr}_{2}$ phases, which did not grow 
significantly during the HIP. Jue et al. [22] also evaluated the HIP-bonded monolithic fuels with $\mathrm{Zr}$ diffusion barriers. Microstructure of decomposed U-Mo region (e.g., $\gamma-\mathrm{U} \rightarrow \alpha-\mathrm{U}+\mathrm{U}_{2} \mathrm{Mo}$ eutectoid) depended on the rolling direction. Jue et al. [22] also postulated that the $\mathrm{Mo}_{2} \mathrm{Zr}$ precipitates formed by the reaction between $\mathrm{UZr}_{2}$ and the U10Mo matrix. Jue et al. [22] furthermore reported complex (i.e., distorted and smeared) microstructure near the edge of the fuel within the cladding and none-Zr-coated fuel region. Huang et al. [23] examined the diffusion couples between U10Mo alloy and pure $\mathrm{Zr}$, but were unable to document any significant interaction at temperature below $700^{\circ} \mathrm{C}$.

Orlov et al. [24] demonstrated the introduction of the carbon impurity by annealing Uranium ingot with carbon isotope additions from 550 to $950^{\circ} \mathrm{C}$. They concluded that the carbon impurity diffused into the uranium, and formed both the UC within uranium and $\mathrm{U}(\mathrm{CO})$ on the surface of the uranium. According to Nomine et al. [25], low solubility of each impurity in uranium causes chemical compound such as the randomly distributed UC phase in U-Mo alloy. Burkes et al. [25] examined the mechanical behaviors of U10Mo alloy with carbon, nitrogen and oxygen impurities, and concluded that the failure mode from tensile test was sensitive to impurity content. Hoge [27] also found that carbon content below $250 \mathrm{ppm}$ is desired to prevent reduction of ductility and tensile strength, based on deleterious mechanical effects of carbon on U10Mo alloys. The focus on current investigation is on the influence of $\mathrm{UC}$ and $\mathrm{UO}_{2}$ on the diffusional bonding of U10Mo and Zr through co-rolling and HIP.

In this study, anomalous microstructures in HIP fuel plates were examined by scanning electron microscopy (SEM), transmission electron microscopy (TEM) and X-ray energy dispersive spectroscopy (XEDS). The anomalous features are the U10Mo-Zr bonding with limited interdiffusion and reaction (i.e., absence of distinguishable interaction zone consist of $\alpha$ - 
$\mathrm{U}, \mathrm{Mo}_{2} \mathrm{Zr}$ and $\mathrm{UZr}_{2}$ ) typically impeded by the $\mathrm{UC}$ and $\mathrm{UO}_{2}$ phases randomly present in the U10Mo alloy.

\section{Experimental details}

The U10Mo alloy used in this investigation was fabricated by arc-melting the $\mathrm{U}$ (depleted) and $99.95 \%$ pure Mo. Prior to melting, the U was cleaned with 30\% nitric-acid. The U10Mo alloy was flipped/turned and remelted three times to ensure the homogeneity of compositions in a vacuum of $1.3 \times 10^{-3} \mathrm{~Pa}\left(10^{-5}\right.$ torr $)$ having less than $50 \mathrm{ppm}$ oxygen. Then, the alloy was cast into coupon-shaped ingots using a graphite mold. The alloy had approximate dimension of $88.8 \mathrm{~mm}$ $\times 48.9 \mathrm{~mm} \times 3.2 \mathrm{~mm}$ and a carbon content of approximately $700 \mathrm{ppm}$. This ingot was then acid cleaned using a mixture of nitric and hydrofluoric acid $\left(2.5 \% \mathrm{HF}, 35 \% \mathrm{HNO}_{3}\right.$ and $\left.62.5 \% \mathrm{H}_{2} \mathrm{O}\right)$, and then laminated, in a carbon steel can, using pure $\mathrm{Zr}$ (99.9\% pure) foil with a starting thickness of 250 micrometer on each surface. The commercially-available reactor-grade pure $\mathrm{Zr}$ was etched using $\sim 30 \%$ nitric acid solution prior to lamination. The Zr-laminated U10Mo coupon was pre-heated at $650^{\circ} \mathrm{C}$ for $30 \mathrm{~min}$ in a furnace, and then co-rolled 15 times to a thickness of approximately $0.46 \mathrm{~mm}$. A post-rolling heat treatment was then performed at $650^{\circ} \mathrm{C}$ for $45 \mathrm{~min}$. The hot-rolled/annealed foil was then removed from the can, and cold-rolled to a final thickness of $0.33 \mathrm{~mm}$. The dimension of the final as-rolled foil was approximately $746 \mathrm{~mm}$ $\times 65 \mathrm{~mm} \times 0.33 \mathrm{~mm}$. The total time exposure at $650^{\circ} \mathrm{C}$ was estimated at approximately 130 minutes. The final thickness of the $\mathrm{Zr}$ diffusion barriers on each surface were approximately 25 $\mu \mathrm{m}$. The final as-rolled U-Mo foil was then sectioned into smaller foils. All the small U-Mo foils used in this study were sectioned from the same parent foil. Each foil sample, in general, 
exhibited the same microstructure of the co-rolled U10Mo/Zr laminate [21]. The asrolled/sectioned sample before the HIP process is labeled as sample AR in this study.

Each U10Mo/Zr mini foil was polished, cleaned using nitric and hydrofluoric acid $(2.5 \%$ $\mathrm{HF}, 35 \% \mathrm{HNO}_{3}$ and $62.5 \% \mathrm{H}_{2} \mathrm{O}$ ), rinsed with ethanol, and stacked with AA6061 (in wt.\% nominal composition of $0.6 \mathrm{Si}-0.35 \mathrm{Fe}-0.28 \mathrm{Cu}-0.08 \mathrm{Mn}-1.0 \mathrm{Mg}-0.20 \mathrm{Cr}-0.13 \mathrm{Zn}-0.08 \mathrm{Ti}-\mathrm{Al}$ balance) cladding pieces and HIP'ed at various temperatures (520, 540, 560 and $580{ }^{\circ} \mathrm{C}$ ) and durations (45, 60, 90180 and 345 minutes). Before the HIP'ing process, the AA6061 cladding was etched using a $1.85 \mathrm{M} \mathrm{NaOH}$ rinse, followed by pickling in $30 \%$ nitric acid in order to remove the residual oxide scale on the $\mathrm{Al}$ alloy surface. The U10Mo/Zr/AA6061 assemblies were then inserted into stainless steel HIP cans with tool steel strong-backs that were welded with corners open for degassing in an argon atmosphere glove box. The assemblies were leak checked and vacuum degassed at $315^{\circ} \mathrm{C}$ for $3 \mathrm{~h}$. The HIP can was then loaded into a laboratory-size HIP, and heated to the target temperature with a ramp-up and cool-down rate of $280^{\circ} \mathrm{C}$ per hour. The isostatic pressure of the HIP process was kept constant at $103 \mathrm{MPa}(15 \mathrm{ksi})$ in an argon environment. Schematic illustrations of the co-rolling and HIP processes are presented in Figure 1 [21], and the samples examined in this study are listed in Table I.

The fabricated fuel plates were then cross-sectioned and mounted in epoxy. The mounted fuel plates were polished using silicon carbide papers (240, 600, 800 and 1200 grit) with an ethanol lubricant and subsequently final polishing was carried out utilizing diamond pastes (3 and $1 \mu \mathrm{m}$ ) with an oil lubricant in a glove box under Ar atmosphere, preventing oxidation and contamination. Microstructural features at the U10Mo-Zr interface were examined by using Zeiss ULTRA-55 FEG SEM with XEDS. Transmission electron microscopy (FEI/Tecnai ${ }^{\text {TM }}$ F30) equipped with Fischione ${ }^{\mathrm{TM}}$ high angle annular dark-field (HAADF) and XEDS was used to 
examine the detailed microstructure and identify the phase constituents via selected area electron diffraction (SAED) and high resolution TEM (HRTEM). The TEM samples were prepared by focused ion beam and in-situ lift-out was utilized for extraction (FIB-INLO; FEITM TEM200) using site-specific capability. Typical phase constituents and microstructural development in these samples as a function of HIP temperature and time were reported previously [21]. This paper reports, in detail, the anomalies, as defined above, observed in these fuel plate samples. Quantitative measure of microstructural features, such as areal percent of inclusions phases within the U10Mo alloy and linear percent of interface with limited interdiffusion-reaction, was carried out for the entire cross-sectional areas $(25.4 \mathrm{~mm} \times 0.33 \mathrm{~mm})$ and interfacial length $(25.4$ mm on both sides) using various and appropriate magnifications.

\section{Phase Constituents and Microstructure of Anomalous Features}

Figure 2(a) shows typical BSE micrographs from the U10Mo monolithic fuel clad in AA6061 with Zr barrier. Typically, the interdiffusion zone between the U10Mo alloy and $\alpha-\mathrm{Zr}$ diffusion barrier consisted of $\mathrm{UZr}_{2}$ layer, discrete $\mathrm{Mo}_{2} \mathrm{Zr}$ and $\alpha-\mathrm{U}$ layer near the $\mathrm{U} 10 \mathrm{Mo} / \mathrm{Zr}$ interface [21] as shown in Figure 2(b) with relatively uniform thickness. However, there were several randomly-distributed inclusions (identified as $\mathrm{UC}$ and $\mathrm{UO}_{2}$ by TEM) observed within the U10Mo alloys, and some located near the interface between the U10Mo alloy and $\alpha-Z r$ diffusion barrier appeared to influence the phase and microstructural development. Figure 3 presents BSE micrographs that are considered "microstructural anomalies" in this investigation: Figure 3(a) presents a BSE micrograph from the region where apparent presence of these inclusions has limited the interdiffusion and reaction between U10Mo and $\mathrm{Zr}$ diffusion barrier; Figure 3(b) presents a BSE micrograph from the region where limited interdiffusion and reaction was 
observed between U10Mo and $\mathrm{Zr}$ diffusion barrier without the apparent presence of the inclusions, at least by SEM. Two TEM samples were prepared by FIB-INLO as indicated in in Figure 3 to elucidate the phase constituents of the inclusions and characterize the regions of limited interdiffusion and reaction. The region of limited interaction in Figure 3(a) to the righthand-side of the apparent $\mathrm{UC}$ and $\mathrm{UO}_{2}$ inclusions, is assumed to be similar to that presented in Figure 3(b) studies by TEM.

Figure 4 presents (a) HAADF scanning TEM (STEM) and (b) BF micrographs of inclusions in TEM sample prepared from Figure 3(a). The UC phase was identified via SAED patterns along the $[\overline{1} 12]$ and $[1 \overline{1} \overline{1}]$ beam directions as shown in Figure 5 . The $\mathrm{UO}_{2}$ phase, consisted of many fine grains, some containing a significant amount of $\mathrm{C}$, was identified by HRTEM micrographs with fast Fourier transformation (FFT) analyses as presented in Figure 6. The UC and $\mathrm{UO}_{2}$ phases were identified as cF8, Fm-3m (225) with a $=4.955 \AA$ and $\mathrm{cF} 12, \mathrm{Fm}-$ $3 \mathrm{~m}$ (225) with a $=5.467 \AA$, respectively. The crystallographic details for the $\mathrm{UC}$ and $\mathrm{UO}_{2}$ phases along with typical chemical compositions observed by semi-quantitative standard-less XEDS are reported in Table II.

Figure 7 shows HAADF micrograph from the TEM sample that had limited interdiffusion and reaction between the U10Mo and $\mathrm{Zr}$ diffusion barrier without the apparent presence of the inclusions. Although not observed by SEM, a significant amount of $\mathrm{UC}$ and $\mathrm{UO}_{2}$ phases were identified on the U10Mo fuel next to Zr barrier as "varying" contrasts (i.e., composition and orientation sensitive) in Figure 7. Figure 8(a) shows that the presence of $\mathrm{UC}$ and $\mathrm{UO}_{2}$ phases near the surface of U10Mo in contact with $\mathrm{Zr}$ barrier by BF TEM micrograph. Both $\mathrm{UC}$ and $\mathrm{UO}_{2}$ phases were confirmed by FFT analyses as presented in Figure 8(b) and 8(c). Figure 9 shows the XEDS elemental mapping from the region shown in Figure 7. Presence of $\mathrm{UC}$ and $\mathrm{UO}_{2}$ phases 
near the $\mathrm{Zr}$ within the $\gamma$-phase U10Mo alloy is distinguished by Mo depletion, while distinction between the $\mathrm{UC}$ and $\mathrm{UO}_{2}$ is apparent by contrast in $\mathrm{U}$ content: higher in $\mathrm{UC}$ than $\mathrm{UO}_{2}$.

\section{Microstructural Anomalies and Fuel Fabrication}

The UC and $\mathrm{UO}_{2}$ phases in the U10Mo alloy matrix were observed in all fuel plate samples listed in Table I. Figure 10 shows BSE micrograph with highlights that distinguishes the $\mathrm{UC}$ and $\mathrm{UO}_{2}$ phases. Although the morphology of the $\mathrm{UC}$ and $\mathrm{UO}_{2}$ phases clearly influenced by the co-rolling, it is assumed that the area percent by image analysis approximate the volume percent for these phases with limited plasticity. Area percent of the $\mathrm{UC}$ and $\mathrm{UO}_{2}$ estimated for all samples examined in this study are listed in Table I. The amount of these inclusions did not change during HIP: as a function of time at $560^{\circ} \mathrm{C}$ as presented in Figure $11(\mathrm{a})$; and as a function of temperature after 90 minutes as presented in Figure 11(b). Therefore the $\mathrm{UC}$ and $\mathrm{UO}_{2}$ phases are presumed to come from the initial casting process, and their amount is not altered by HIP.

In all samples examined in this study, regions of limited interdiffusion and reaction were observed as presented in Figure 3(b). They were observed typically with the presence of UC and $\mathrm{UO}_{2}$ phases as presented in Figures 7,8 and 9. The linear length of these regions and the total length of the fuel alloy in contact with $\mathrm{Zr}$ barrier were measured to estimate the linear percent of regions where the interdiffusion and reaction were significantly impeded. Figure 12 shows an example to illustrate how the fractional linear length of the limited interdiffusion-reaction zone was measured (i.e., $\mathrm{L}_{\mathrm{i}} / \mathrm{L}_{\mathrm{T}}$ ) over the entire fuel plate sample. Table I reports the percent of length associated with limited interdiffusion and reaction. Standard deviation in percent measurement was obtained by three independent measurements. 
Figure 13(a) presents the amount of region with limited interdiffusion and reaction as a function of HIP temperature with a constant holding time of 90 minutes. Despite the interference of the $\mathrm{UC}$ and $\mathrm{UO}_{2}$ phases on the interdiffusion and reaction, there is a noticeable decrease in this microstructural anomaly as a function of temperature. However as a function of HIP time at $560^{\circ} \mathrm{C}$, no observable trend was observed as shown in Figure 13(b). A decrease in the amount of regions with limited interdiffusion and reaction may involve complex phenomena including oxide/carbide break-up, thermally-activated interdiffusion via lattice and interfaces with geometrical barriers, nucleation and growth. Within the parameters of temperature and time variation in this study, only the temperature dependence was observed.

The $\mathrm{UC}$ and $\mathrm{UO}_{2}$ phases in the U10Mo alloy appear to originate from the $\mathrm{C}$ and $\mathrm{O}$ impurities during the casting based on this investigation [24,25]. Amount of these inclusions did not change during HIP within the U10Mo alloy. Their presence near the surface of the U10Mo alloy in contract with $\mathrm{Zr}$ diffusion barrier impeded the interdiffusion and reaction that produce $\mathrm{UZr}_{2}$ layer, discrete $\mathrm{Mo}_{2} \mathrm{Zr}$ and $\alpha$-U layer after HIP. However the region of limited interdiffusion and reaction disappeared noticeably with an increase in HIP temperature, however not with longer HIP duration examined in this study.

Distribution of $\mathrm{UC}$ and $\mathrm{UO}_{2}$ inclusions in the U10Mo fuel alloy can cause unexpected physical, mechanical and chemical behavior of the monolithic fuel plate [24-27]. This manuscript reported some anomalies in chemical interactions between the fuel alloy and $\mathrm{Zr}$ diffusion barrier. Table II, in addition to crystallographic details and compositions, lists some of the physical and mechanical properties for the UC, $\mathrm{UO}_{2}$ and $\gamma(\mathrm{U}-10 \mathrm{wt} \%$ Mo) phases [24-34]. During the fabrication of the monolithic fuel plate, large differences in elastic modulus and 
hardness may cause crack formation within the low-toughness phase. Cracks were frequently observed in the $\mathrm{UO}_{2}$ phase as presented in Figures 3 and 4 in this study.

\section{Summary}

The microstructural anomalies in the U10Mo fuel alloy and near the interface between the U10Mo fuel alloy and Zr diffusion barrier were examined by SEM and TEM/STEM. The cF8, Fm-3m (225) UC phase and cF12, Fm-3m (225) $\mathrm{UO}_{2}$ phase were identified to be distributed through out the U10Mo alloy. Volume percent of these inclusions ranged from 0.5 to 1.8 , and did not change as functions of HIP temperature and time. The presence of $\mathrm{UC}$ and $\mathrm{UO}_{2}$ inclusions near the surface of the U10Mo alloy in contract with $\mathrm{Zr}$ diffusion barrier produced regions of limited interdiffusion and reaction observed by cross-sectional microscopy. HIP at higher temperature partially removed these regions of impeded interdiffusion and reaction. However within the HIP duration examined in this study at constant temperature of $560^{\circ} \mathrm{C}$, no noticeable change was observed as a function of time. Difference in physical, mechanical and chemical properties/interactions of $\mathrm{UC}, \mathrm{UO}_{2}$, and $\gamma$-U10Mo phases can influence structural integrity of the U10Mo monolithic fuel with $\mathrm{Zr}$ diffusion barrier.

\section{Acknowledgments}

The work was supported by the US Department of Energy under DOE-NE Idaho Operations Office Contract DE-AC07-05ID14517 administered by Battelle Energy Alliance, LLC. The U. S. Government retains and the publisher, by accepting the article for publication, acknowledges that the U. S. Government retains a nonexclusive, paid-up, irrevocable, world- 
wide license to publish or reproduce the published form of this manuscript, or allow others to do so, for U.S. Government purposes.

\section{U. S. Department of Energy Disclaimer}

This information was prepared as an account of work sponsored by an agency of the U. S. Government. Neither the U. S. Government nor any agency thereof, nor any of their employees, makes any warranty, express or implied, or assumes any legal liability or responsibility for the accuracy, completeness, or usefulness of any information, apparatus, product, or process disclosed, or represents that its use would not infringe privately owned rights. References herein to any specific commercial product, process, or service by trade name, trademark, manufacturer, or otherwise, does not necessarily constitute or imply its endorsement, recommendation, or favoring by the U. S. Government or any agency thereof. The views and opinions of authors expressed herein do not necessarily state or reflect those of the U. S. Government or any agency thereof.

\section{References}

[1] J.L. Snelgrove, G.L. Hofman, M.K. Meyer, C.L. Trybus, T.C. Wiencek, "Development of very-high-density low-enriched-uranium fuels," Nuclear Engineering and Design, 178 (1997) 119-126.

[2] M.K. Meyer, G.L. Hofman, S.L. Hayes, C.R. Clark, T.C. Wiencek, J.L. Snelgrove, R.V. Strain, and K.H. Kim, "Low-temperature irradiation behavior of uranium-molybdenum alloy dispersion fuel," Journal of Nuclear Materials, 304 (2002) 221-236.

[3] D.D. Keiser, Jr., S.L. Hayes, M.K. Meyer, C.R. Clark, "High-density, low-enriched uranium fuel for nuclear research reactors," Journal of Metals (JOM), 55 (2003) 55-58.

[4] D.M. Wachs, "RERTR Fuel Development and Qualification Plan," INL/EXT-05-01017, Idaho National Laboratory, Idaho, USA, 2007.

[5] S. Van Den Berghe, A. Leenaers, E. Koonen, L. Sannen, "From High to Low Enriched Uranium Fuel in Research Reactors," Advances in Science and Technology, 73 (2010) 7890 . 
[6] D. Wachs, D. Keiser, M. Meyer, D. Burkes, C. Clark, G. Moore, J.-F. Jue, T. Totev, G. Hofman, T. Wiencek, Y.S. Kim, J. Snelgrove, "High Density Fuel Development for Research Reactors," Global 2007 - Advanced Nuclear Fuel Cycles and Systems, 2007.

[7] A. Leenaers, S. Van den Berghe, E. Koonen, C. Jarousse, F. Huet, M. Trotabas, M. Boyard, S. Guillot, L. Sannen, M. Verwerft, "Post-irradiation examination of uranium-7 wt\% molybdenum atomized dispersion fuel," Journal of Nuclear Materials, 335 (2004) 39-47.

[8] Y.S. Kim, G.L. Hofman, J.S. Cheon, "Mechanical modeling of U-Mo fuel swelling in monolithic plates," RERTR-2012 - The 34th Interational Meeting on Reduced Enrichment for Research and Test Reactors, Warsaw, Poland, 2012.

[9] M.K. Meyer, G.L. Hofman, S.L. Hayes, C.R. Clark, T.C. Wiencek, J.L. Snelgrove, R.V. Strain, K.H. Kim, "Low-temperature irradiation behavior of uranium-molybdenum alloy dispersion fuel," Journal of Nuclear Materials, 304 (2002) 221-236.

[10] H. Palancher, P. Martin, V. Nassif, R. Tucoulou, O. Proux, J.-L. Hazemann, O. Tougait, E. Lahera, F. Mazaudier, C. Valot, S. Dubois, "Evidence for the presence of U-Mo-Al ternary compounds in the U-Mo/Al interaction layer grown by thermal annealing: a coupled micro X-ray diffraction and micro X-ray absorption spectroscopy study," Journal of Applied Crystallography, 40 (2007) 1064-1075.

[11] H. Ryu, J. Park, C. Kim, Y. Kim, G. Hofman, "Diffusion reaction behaviors of U-Mo/Al dispersion fuel," Journal of Phase Equilibria and Diffusion, 27 (2006) 651-658.

[12] F. Mazaudier, C. Proye, F. Hodaj, "Further insight into mechanisms of solid state interactions in UMo/Al system," Journal of Nuclear Materials, 377 (2008) 476-485.

[13] E. Perez, D.D. Keiser, Jr., Y.H. Sohn, "Phase constituents and microstructure of interaction layer formed in U-Mo alloys vs. Al diffusion couple annealed at $600^{\circ} \mathrm{C}$," Metallurgical and Materials Transactions A, 42 (2011) 3071-3083.

[14] B. Yao, E. Perez, D.D. Keiser Jr, J.-F. Jue, C.R. Clark, N. Woolstenhulme, Y.H. Sohn, "Microstructure characterization of as-fabricated and $475^{\circ} \mathrm{C}$ annealed U-7wt.\%Mo dispersion fuel in Al-Si alloy matrix," Journal of Alloys and Compounds, 509 (2011) $9487-$ 9496.

[15] D.D. Keiser Jr, J.-F. Jue, B. Yao, E. Perez, Y. Sohn, C.R. Clark, "Microstructural characterization of U-7Mo/Al-Si alloy matrix dispersion fuel plates fabricated at $500^{\circ} \mathrm{C}$," Journal of Nuclear Materials, 412 (2011) 90-99.

[16] E. Perez, B. Yao, D.D. Keiser Jr, Y.H. Sohn, "Microstructural Analysis of As-Processed U10wt.\%Mo Monolithic Fuel Plate in AA6061 Matrix with Zr Diffusion Barrier," Journal of Nuclear Materials, 402 (2010) 8-14.

[17] G.A. Moore, M.C. Marshall, "Co-rolled U10Mo/Zirconium-barrier layer monolithic fuel foil fabrication,” INL/EXT-10-17774, Idaho National Laboratory, 2010.

[18] G.A. Moore, F.J. Rice, N.E. Woolstenhulme, J.F. Jue, B.H. Park, S.E. Steffler, N.P. Hallinan, M.D. Chapple, M.C. Marshall, B.I. Mackowiak, C.R. Clark, B.H. Rabin, "Monolithic fuel fabrication process development at the Idaho National Laboratory," INL/CON-09-17298, Idaho National Laboratory, Idaho, USA, 2009.

[19] K.H. Kim, S.J. Oh, D.B. Lee, C.K. Kim, D.S. Sohn, "Continous casting of wide U7wt.\%Mo alloy foils for a monolithic fuel by a single cooling roll," Transactions of the 10th International Topical Meeing on Research Reactor Fuel Management, European Nuclear Society, Sofia, Bulgaria, 2006, 83-86. 
[20] A.B. Robinson, G.S. Chang, D.D. Keiser Jr, D.M. Wachs, D.L. Porter, "Irradition performance of U-Mo alloy based monlithic plate-type fuel - design selection," INL/EXT09-16807, Idaho National Laboratory, Idaho, USA, 2009.

[21] Y. Park, J. Yoo, K. Huang, D.D. Keiser Jr, J.F. Jue, B. Rabin, G. Moore, Y.H. Sohn, "Growth kinetics and microstructural evolution during hot isostatic pressing of U-10 wt.\% Mo monolithic fuel plate in AA6061 cladding with $\mathrm{Zr}$ diffusion barrier," Journal of Nuclear Materials, 447 (2014) 215-224.

[22] J.-F. Jue, D.D. Keiser Jr, C.R. Breckenridge, G.A. Moore, M.K. Meyer, "Microstructural characteristics of HIP-bonded monolithic nuclear fuels with a diffusion barrier," Journal of Nuclear Materials, 448 (2014) 250-258.

[23] K. Huang, Y. Park, D.D. Keiser, Jr., Y.H. Sohn, "Interdiffusion between Zirconium Diffusion Barrier and Uranium-Molybdenum Alloy," Journal of Phase Equilibria and Diffusion, Vol. 33 (2012) pp. 443-449.

[24] V.K. Orlov, V.S. Sergeev, M.A. Fomishkin, A.A. Rostovtsev, A.K. Kruglov, "Carbon diffusion in Uranium during thermal reprocessing in vacuum," Atomic Energy, 95 (2003) 536-539.

[25] A.M. Nomine, D. Bedere, D. Miannay, 1974. The influence of physio-chemical parameters on the mechanical properties of some isotropic uranium alloys. In: Burke, J.J., Colling, D.A., Gorum, A.E., Greenspan, J. (Eds.), Proceedings of the Third Army Materials Technical Conference, Physical Metallurgy of Uranium Alloys. Vail, CO, pp. 657-699.

[26] D.E. Burkes, R. Prabhakaran, T. Hartmann, J.-F. Jue, F.J. Rice, "Properties of DU-10 wt\% Mo alloys subjected to various post-rolling heat treatments," Nuclear Engineering and Design, 240 (2010) 1332-1339.

[27] K.G. Hoge, "Some mechanical properties of U-10\% Mo alloy under dynamic tension loads," Journal of Basic Engineering, 6 (1966) 509-517.

[28] A.C. Secrest, Jr., E.L. Foster, R.F. Dickerson, "Preparation and Properties of Uranium monocarbide castings," BMI-1309, 1959.

[29] J. Belle, Uranium Dioxide: Properties and Nuclear Applications, United States Atomic Energy Commission, Washington, DC., 1981.

[30] S. Van den Berghe, A. Leenaers, C. Detavernier, "The SELENIUM Fuel Experiment Progress Report after Two Cycles," RERTR 2012 - 34th International Meeting on Reduced Enrichment for Research and Test Reactors, Warsaw, Poland, 2012.

[31] G.A. Meerson, R.B. Kotel'nikov, S.N. Bashlykov, "Uranium monocarbide,” Journal of Nuclear Energy. Parts A/B. Reactor Science and Technology, 16 (1962) 485-488.

[32] S.M. Lang, F.P. Knudsen, C.L. Fillmore, R.S. Roth, High-temperature reactions of uranium dioxide with various metal oxides, U.S. Government Printing Office, 1956.

[33] H. Okamoto, "Molybdenum-Uranium," Journal of Phase Equilibria and Diffusion, 33 (2012) 497-497.

[34] B.R.T. Frost, “The carbides of uranium," Journal of Nuclear Materials, 10 (1963) 265-300.

[35] F.A. Halden, H.C. Wohlers, and R.H. Reinhart, "Thermal expansion of uranium dioxide," Final Report SRI/TDI-5722, 1959.

[36] D.E. Burkes, G.S. Mickum, D.M. Wachs, "Thermophysical Properties of U-10Mo Alloy," INL/EXT-10-19373, Idaho National Laboratory, Idaho, USA, 2010.

[37] G. Beghi, Gamma phase uranium-molybdenum fuel alloys, European Atomic Energy Community, 1968. 
Table I. HIP plate samples examined in this study along with estimated quantity of microstructural anomalies.

\begin{tabular}{|c|c|c|c|c|}
\hline Sample & $\begin{array}{c}\text { Temperature } \\
\left({ }^{\circ} \mathrm{C}\right)\end{array}$ & $\begin{array}{c}\text { Hold Time } \\
(\mathrm{min})\end{array}$ & $\begin{array}{c}\text { Area percent of the UC and } \\
\mathrm{UO}_{2} \text { phases in U-10Mo }(\%)\end{array}$ & $\begin{array}{c}\text { Limited interdiffusion- } \\
\text { reaction zone (\%) }\end{array}$ \\
\hline AR & N.A. & N.A. & 1.24 & $18.10 \pm 0.54$ \\
\hline $52-90$ & 520 & 90 & 1.53 & $19.90 \pm 0.49$ \\
\hline $54-90$ & 540 & 90 & 0.49 & $16.65 \pm 0.20$ \\
\hline $56-45$ & 560 & 45 & 1.78 & $14.99 \pm 0.39$ \\
\hline $56-60$ & 560 & 60 & 1.18 & $20.47 \pm 0.47$ \\
\hline $56-90$ & 560 & 90 & 1.39 & $11.05 \pm 0.16$ \\
\hline $56-180$ & 560 & 180 & 1.41 & $21.71 \pm 0.51$ \\
\hline $56-345$ & 560 & 345 & 1.64 & $10.90 \pm 0.38$ \\
\hline $58-90$ & 580 & 90 & 1.32 & $9.75 \pm 0.15$ \\
\hline
\end{tabular}

Table II. Crystallographic details, properties, and chemical compositions for the $\mathrm{UC} \mathrm{UO}_{2}$ and $\gamma$ (U-10wt.\%Mo) phases [26, 28-37]. The chemical compositions reported are typical values observed in this study by semi-quantitative standard-less XEDS.

\begin{tabular}{|c|c|c|c|c|}
\hline \multicolumn{2}{|c|}{ Phase } & $\mathrm{UC}$ & $\mathrm{UO}_{2}$ & $\gamma$ (U-10wt.\%Mo) \\
\hline \multicolumn{2}{|c|}{ Pearson Symbol } & $\mathrm{cF} 8$ & $\mathrm{cF} 12$ & $\mathrm{cI} 2$ \\
\hline \multicolumn{2}{|c|}{ Space group } & Fm3m (225) & Fm3m (225) & $\operatorname{Im} 3 m(229)$ \\
\hline \multicolumn{2}{|c|}{ Lattice parameter $(\AA)$} & 4.955 & 5.467 & 3.409 \\
\hline \multicolumn{2}{|c|}{ Elastic modulus $(\mathrm{GPa})^{*}$} & $215.7[28]$ & $172.6[29]$ & $89.2[26]$ \\
\hline \multicolumn{2}{|c|}{$\begin{array}{c}\text { Thermal expansion } \\
\text { coefficient }(/ \mathrm{K})\end{array}$} & $\sim 10^{-5}[28]$ & $\sim 10^{-5}[29]$ & $\sim 10^{-5}[26,30]$ \\
\hline \multicolumn{2}{|c|}{ Melting point $\left({ }^{\circ} \mathrm{C}\right)$} & $2275[31]$ & $2878[32]$ & $\sim 1250[33]$ \\
\hline \multicolumn{2}{|c|}{ Density $\left(\mathrm{g} / \mathrm{cm}^{3}\right)^{*}$} & $13.63[34]$ & $10.27[35]$ & $17.2[36]$ \\
\hline \multicolumn{2}{|c|}{ Hardness $(\mathrm{GPa})^{*}$} & $9.1[31]$ & $6.5[29]$ & $3.1[37]$ \\
\hline \multirow{5}{*}{$\begin{array}{l}\text { Composition } \\
\text { (at.\%) }\end{array}$} & $\mathrm{U}$ & 30.2 & 33.1 & 78.4 \\
\hline & Mo & 2.3 & 2.1 & 21.6 \\
\hline & $\mathrm{Zr}$ & 0.4 & 1.0 & N.A. \\
\hline & $\mathrm{O}$ & 0.0 & 10.2 & N.A. \\
\hline & $\mathrm{C}$ & 67.1 & 53.6 & N.A. \\
\hline
\end{tabular}

* At room temperature 


\section{List of Figures}

[1] Schematic diagrams of (a) co-rolling and (b) hot-isostatic pressing employed in this investigation to produce U-10 wt.\% Mo monolithic fuel encased in AA6061 with $\mathrm{Zr}$ diffusion barrier [21].

[2] Backscatter electron micrographs of the U-10 wt.\% Mo monolithic fuel encased in AA6061 with $\mathrm{Zr}$ diffusion barrier: (a) overall fuel plate assembly, and (b) the interface between U$10 \mathrm{wt} . \%$ Mo and $\mathrm{Zr}$ diffusion barrier, produced by co-rolling and hot-isostatic pressing (sample $56-345$, hot-isostatic pressed at $560^{\circ} \mathrm{C}$ for $345 \mathrm{~min}$ ).

[3] (a) Anomalous microstructure associated with the $\mathrm{UC}$ and $\mathrm{UO}_{2}$ phases, and (b) the imperfect reaction zone in U-10 wt.\% Mo alloy. (From sample 56-345, HIP'ed at $560^{\circ} \mathrm{C}$ for $345 \mathrm{~min})$.

[4] (a) High angle annular dark field (HAADF) scanning transmission electron microscopy (STEM) micrograph and (b) bright field (BF) micrograph from the $\mathrm{UC}$ and $\mathrm{UO}_{2}$ inclusion phases. (TEM specimen prepared from Figure 3(a) from sample 56-345, HIP'ed at $560^{\circ} \mathrm{C}$ for $345 \mathrm{~min}$ ).

[5] Selected area electron diffraction patterns from the UC phase in (a) [112] and (b) [111] beam direction. (TEM specimen prepared from Figure 3(a) from sample 56-345, HIP'ed at $560^{\circ} \mathrm{C}$ for $\left.345 \mathrm{~min}\right)$.

[6] High resolution TEM micrographs with the fast Fourier transform analysis along the<smiles>[C]1[Si][Si][Si]1</smiles>

beam direction for the $\mathrm{UO}_{2}$ phase. (TEM specimen prepared from Figure 3(a) from sample 56-345, HIP'ed at $560^{\circ} \mathrm{C}$ for $345 \mathrm{~min}$ ).

[7] HAADF STEM micrograph of the region with limited interdiffusion and reaction near the interface between the U10Mo alloy and Zr diffusion barrier. Contrast developed by composition and orientation shows UC (white arrows) and $\mathrm{UO}_{2}$ (black arrows) phase. (TEM specimen prepared from Figure 3(b) from sample 56-345, HIP'ed at $560^{\circ} \mathrm{C}$ for 345 $\min )$.

[8] (a) Bright field micrograph and high resolution TEM micrographs with the fast Fourier transform analyses for the (b) $\mathrm{UC}$ and (c) $\mathrm{UO}_{2}$ phases. (TEM specimen prepared from Figure 3(b) from sample 56-345, HIP'ed at $560^{\circ} \mathrm{C}$ for $345 \mathrm{~min}$ ).

[9] XEDS elemental mapping of Figure 7. (TEM specimen prepared from Figure 3(b) from sample 56-345, HIP'ed at $560^{\circ} \mathrm{C}$ for $345 \mathrm{~min}$ ). 
[10] The measurement of area percent for the $\mathrm{UC}$ and $\mathrm{UO}_{2}$ phases distributed in the $\mathrm{U}-10 \mathrm{wt} \%$. Mo alloy.

[11] Estimate volume fraction of the $\mathrm{UC}$ and $\mathrm{UO}_{2}$ inclusion phases distributed in the $\mathrm{U}-10 \mathrm{wt}$. \% Mo monolithic fuel after hot-isostatic pressing (a) at $560^{\circ} \mathrm{C}$ as a function of time, and (b) after 90 minutes as a function of time. "AR" refers to the estimated volume fraction in asrolled sample prior to HIP.

[12] Illustration of the linear measurement for regions with limited interdiffusion and reaction between the U-10 wt.\% Mo alloy and $\mathrm{Zr}$ diffusion barrier.

[13] Estimated area of limited interdiffusion and reaction between the U-10 wt.\% Mo and $\mathrm{Zr}$ diffusion barrier during HIP as (a) a function of temperature after 90 minutes and (b) a function of time at $560^{\circ} \mathrm{C}$. "AR" refers to the estimated volume fraction in as-rolled sample prior to HIP. 


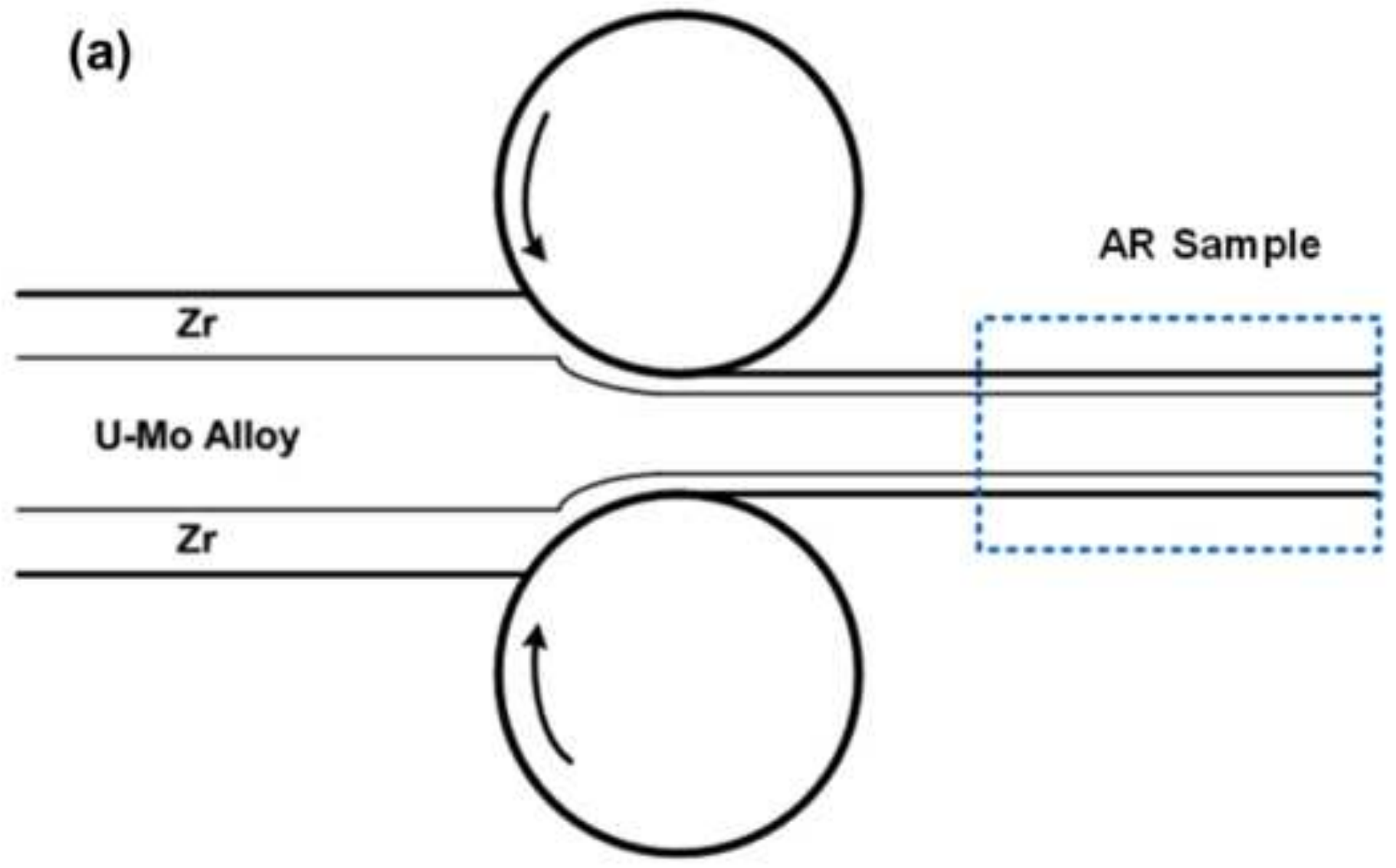

(b)

HIP Pressure $103 \mathrm{MPa}$ (15 ksi)
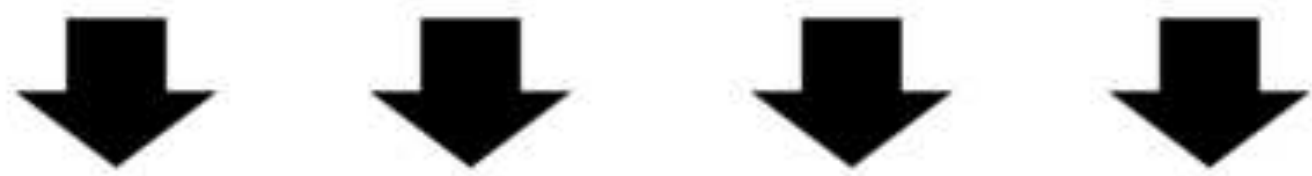

AA6061

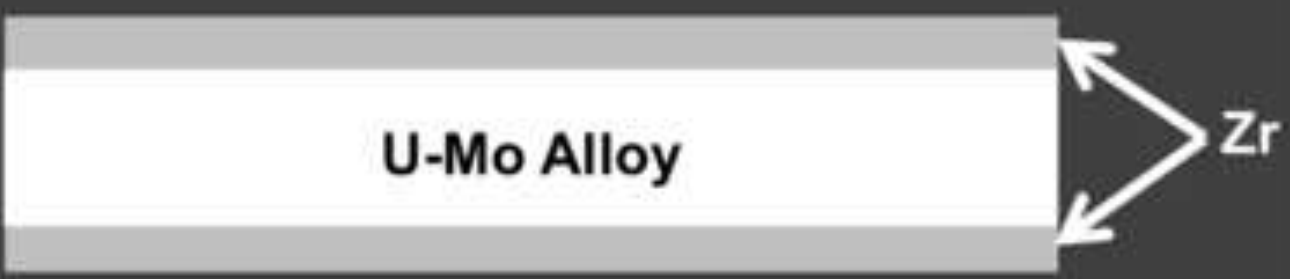

\section{AA6061}
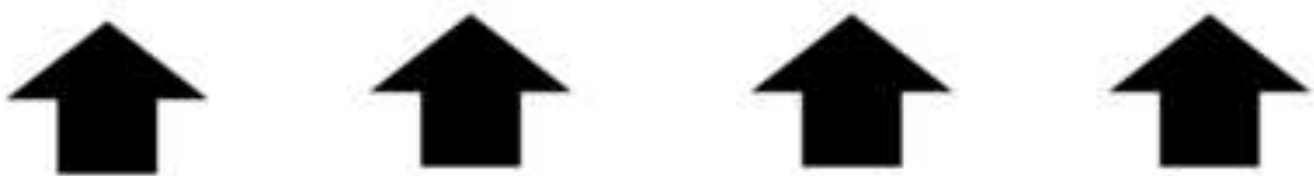

HIP Pressure $103 \mathrm{MPa}$ (15 ksi) 
(a)

\section{AA6061

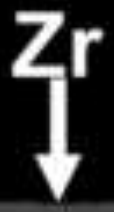

\section{U10Mo}

\section{$100 \mu \mathrm{m}$}

$\mathrm{Zr}$

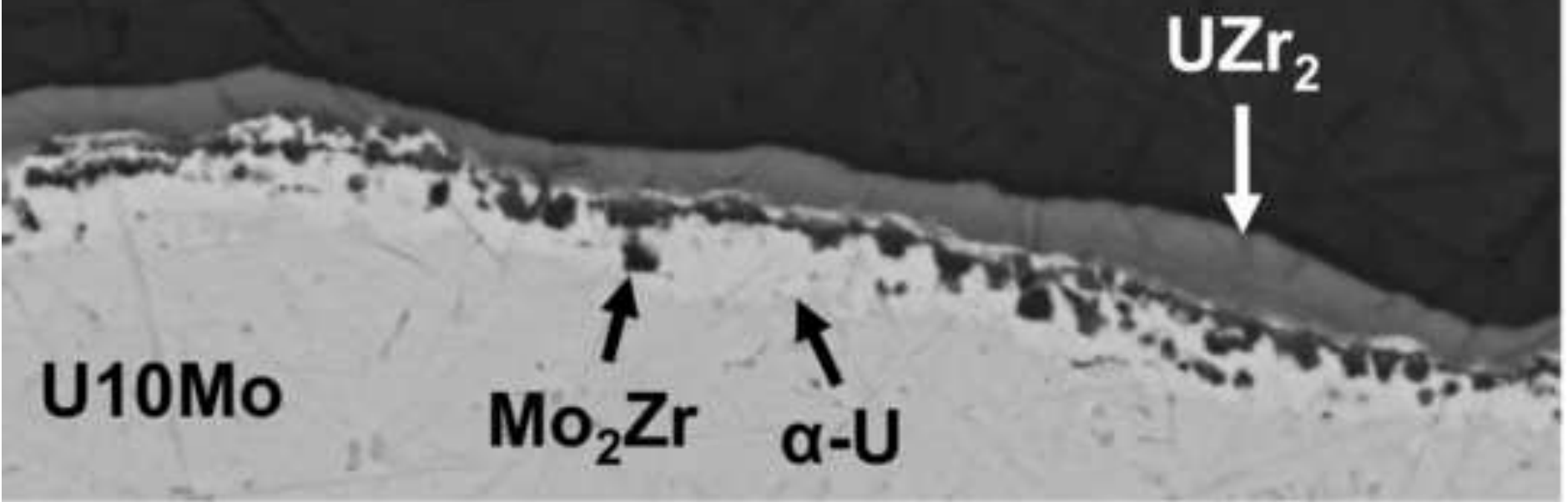


(a)

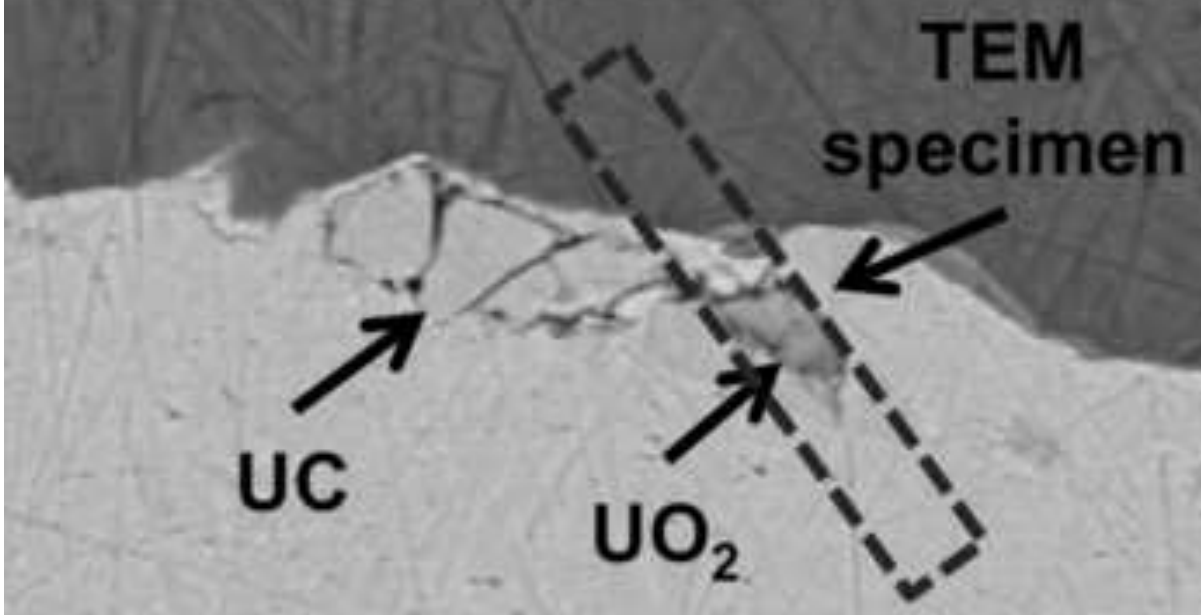

U10Mo

$10 \mu \mathrm{m}$

(b)

$\mathbf{Z r}$

TEM specimen

$\mathrm{UZr}_{2}$

L $\mathrm{Mo}_{2} \mathrm{Zr}$

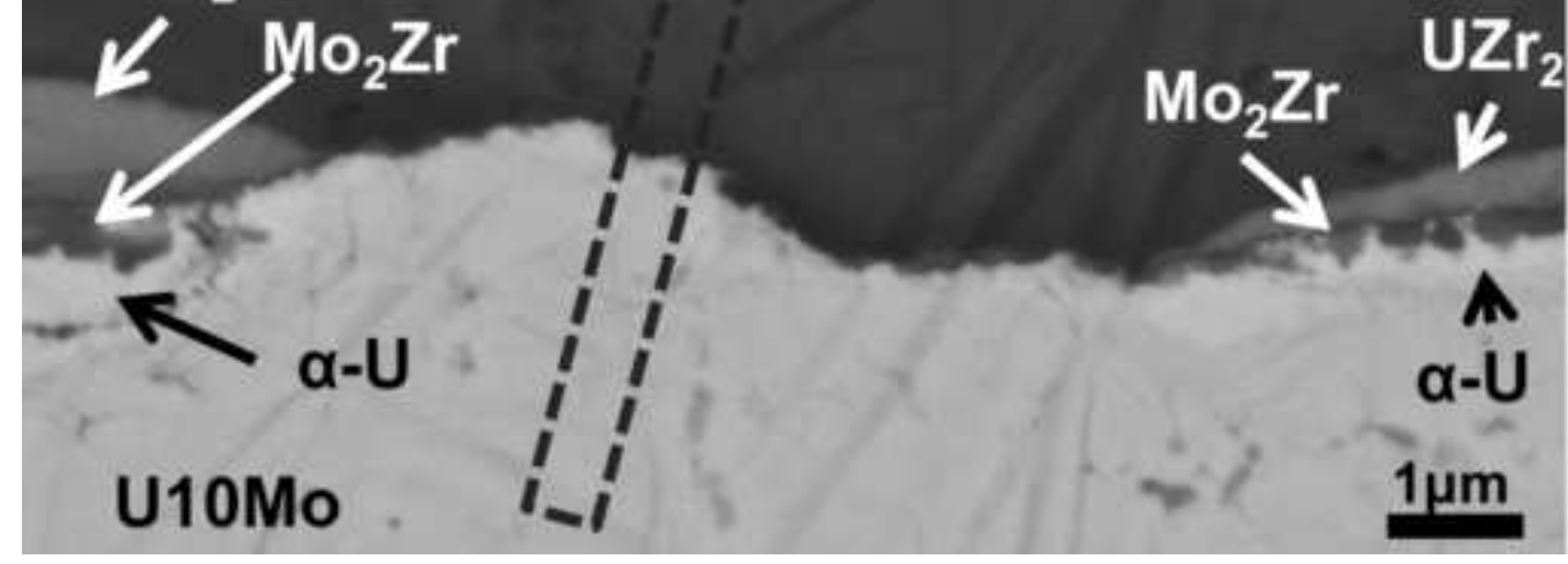

U10Mo 
(a)

\section{UC}

\section{$500 \mathrm{~nm}$}

(b)

\section{UC}


(a)

220311

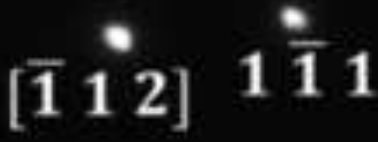

(b)

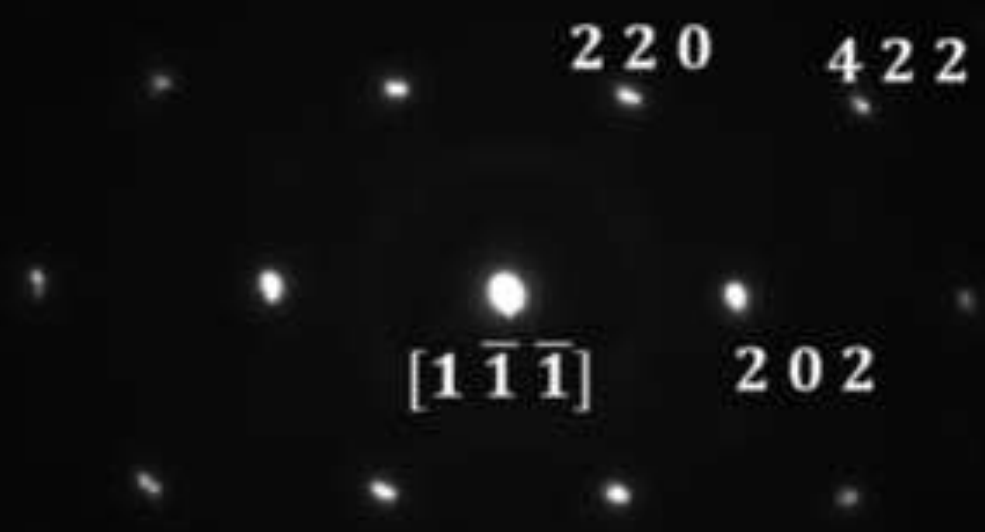

$101 / \mathrm{nm}$

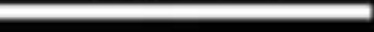



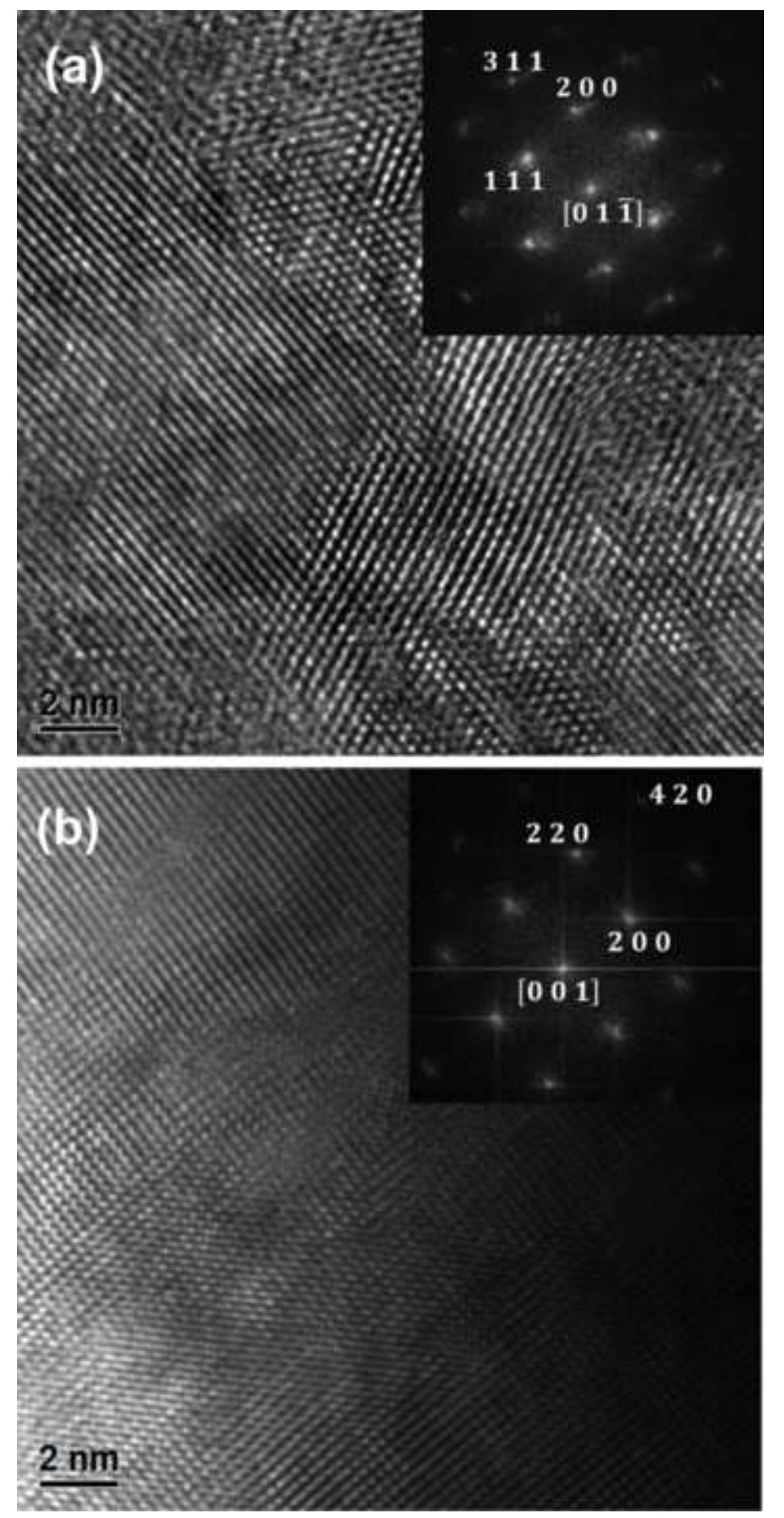

Figure

\section{Figure 6}

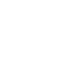

$\mathrm{He}$ (

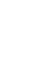

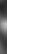

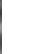

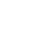




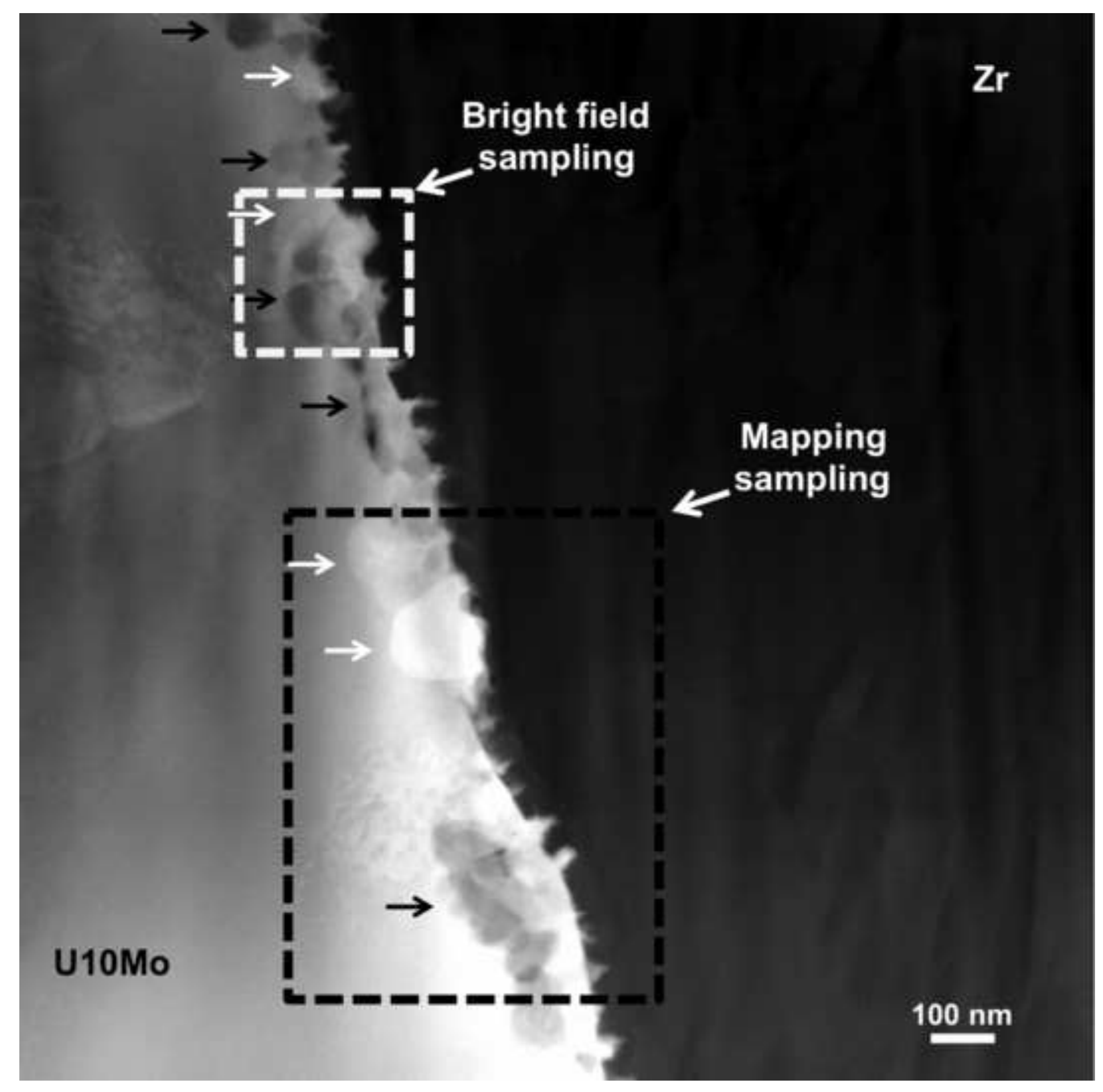


(a)

\section{UC}

$50 \mathrm{~nm}$

\section{$\mathrm{UO}_{2}$}

\section{U10Mo}
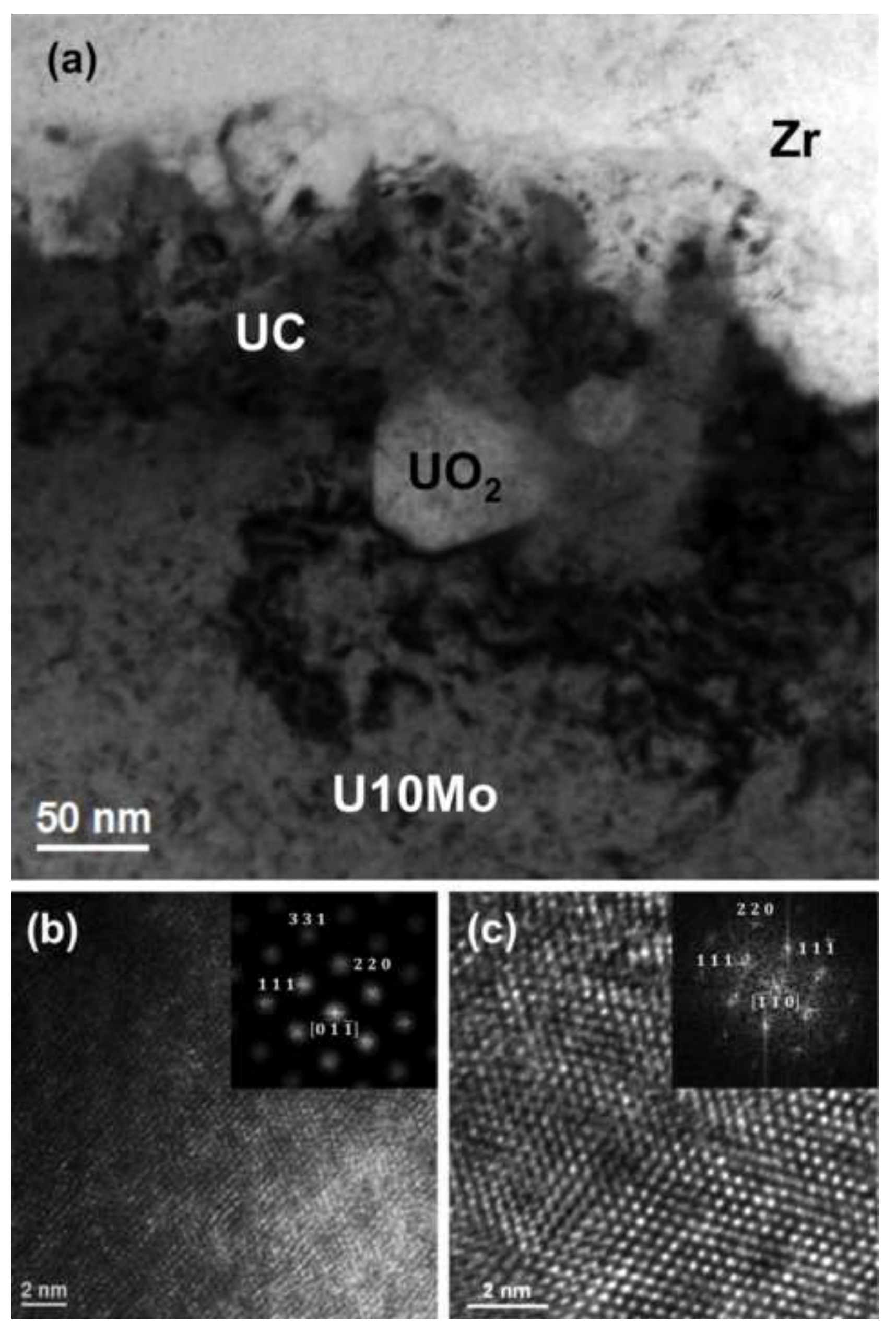

\section{Figure 8}

列
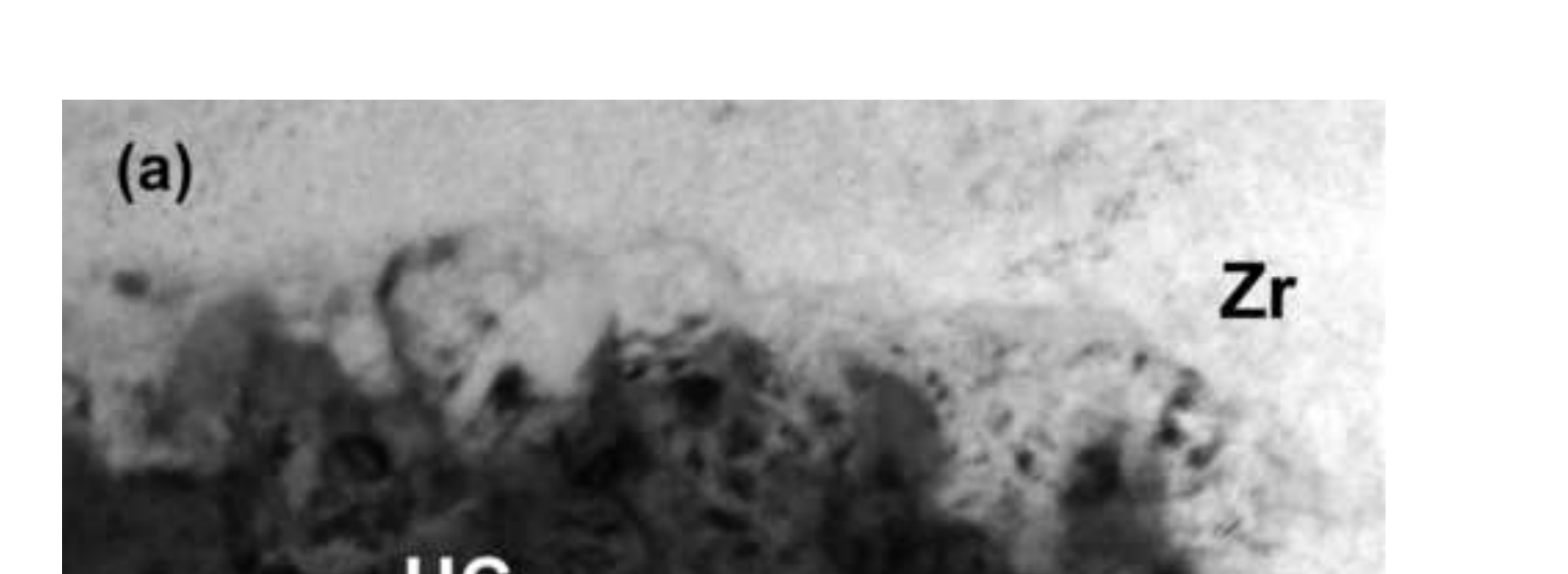


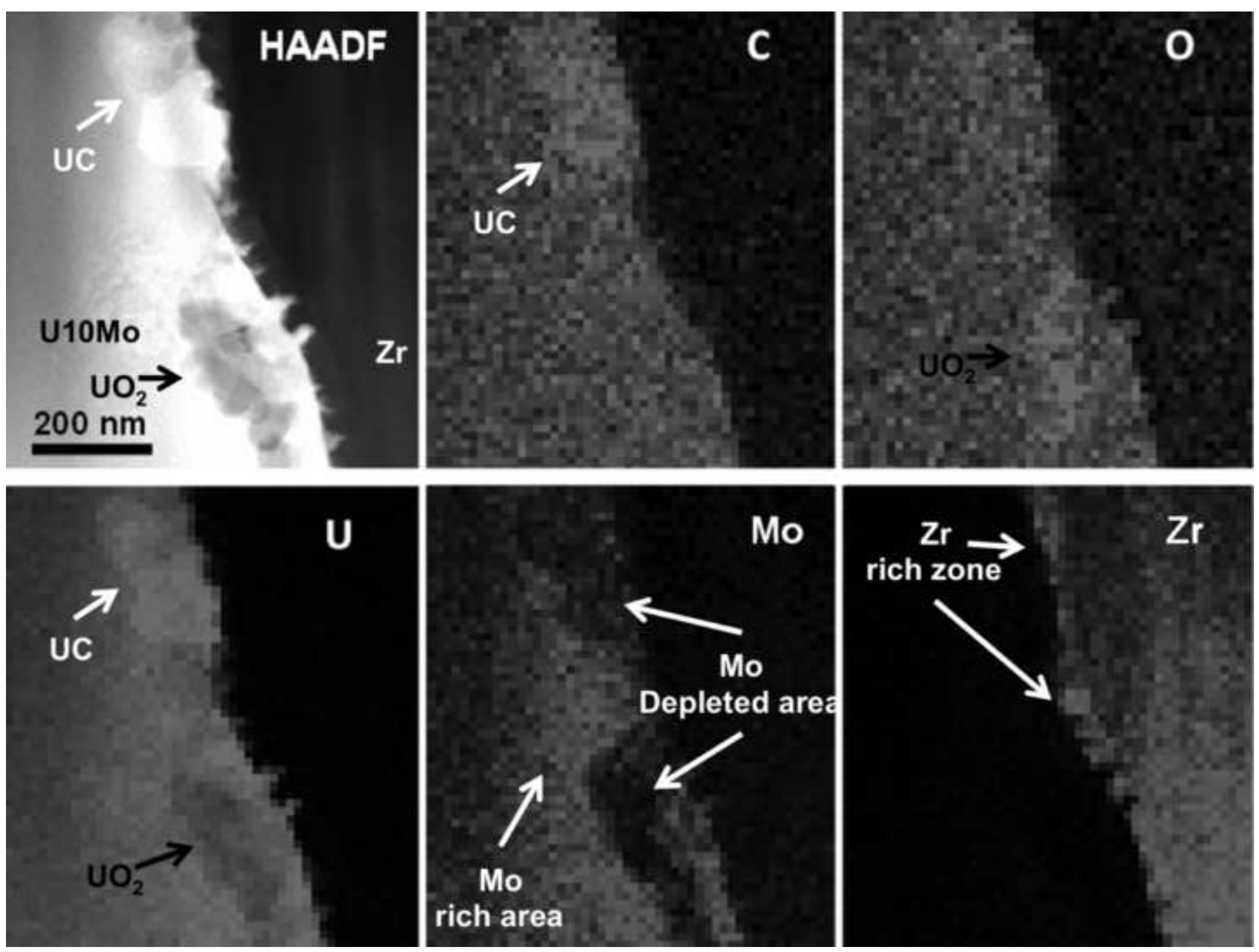




\section{Figure 10}

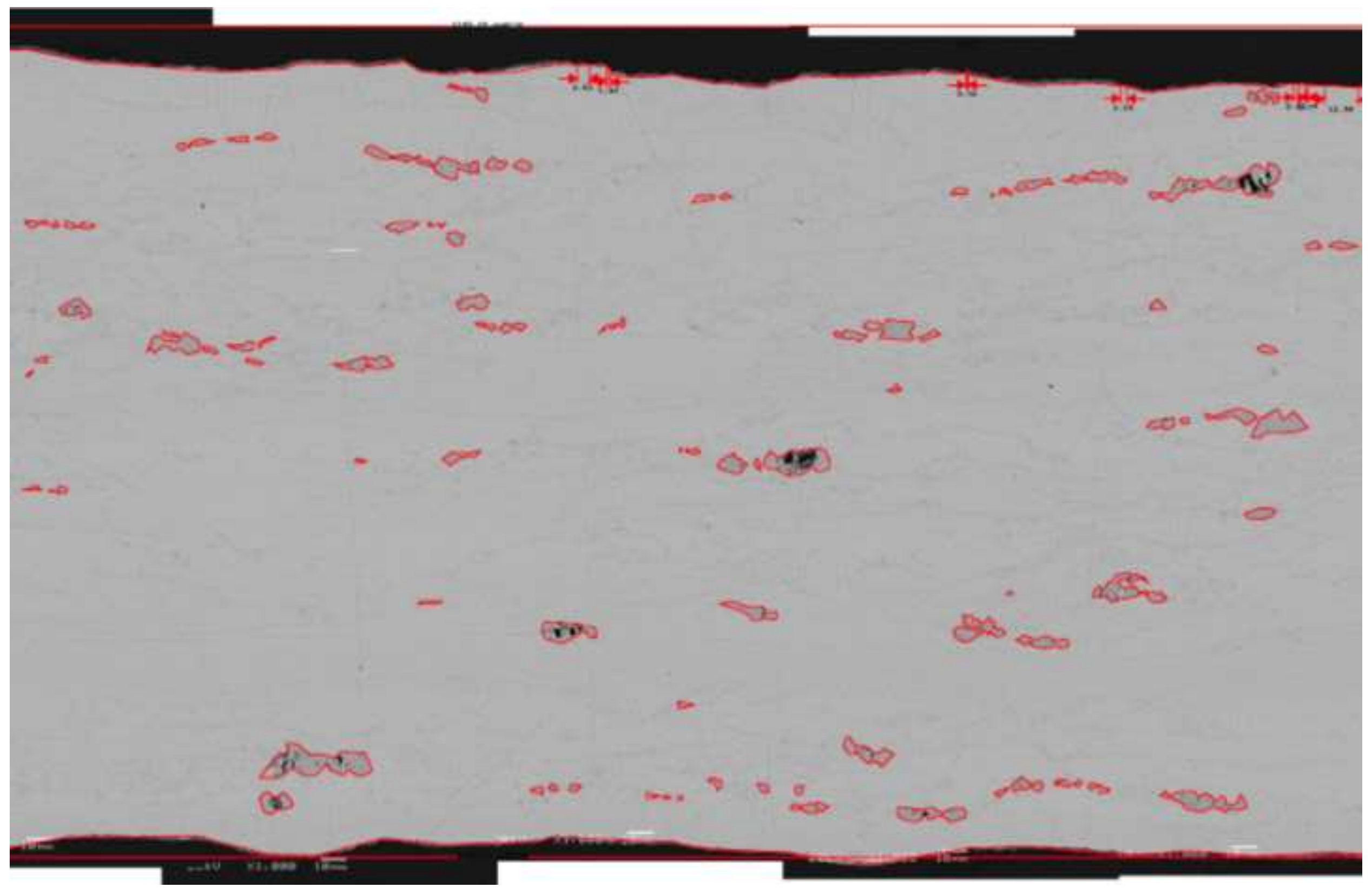



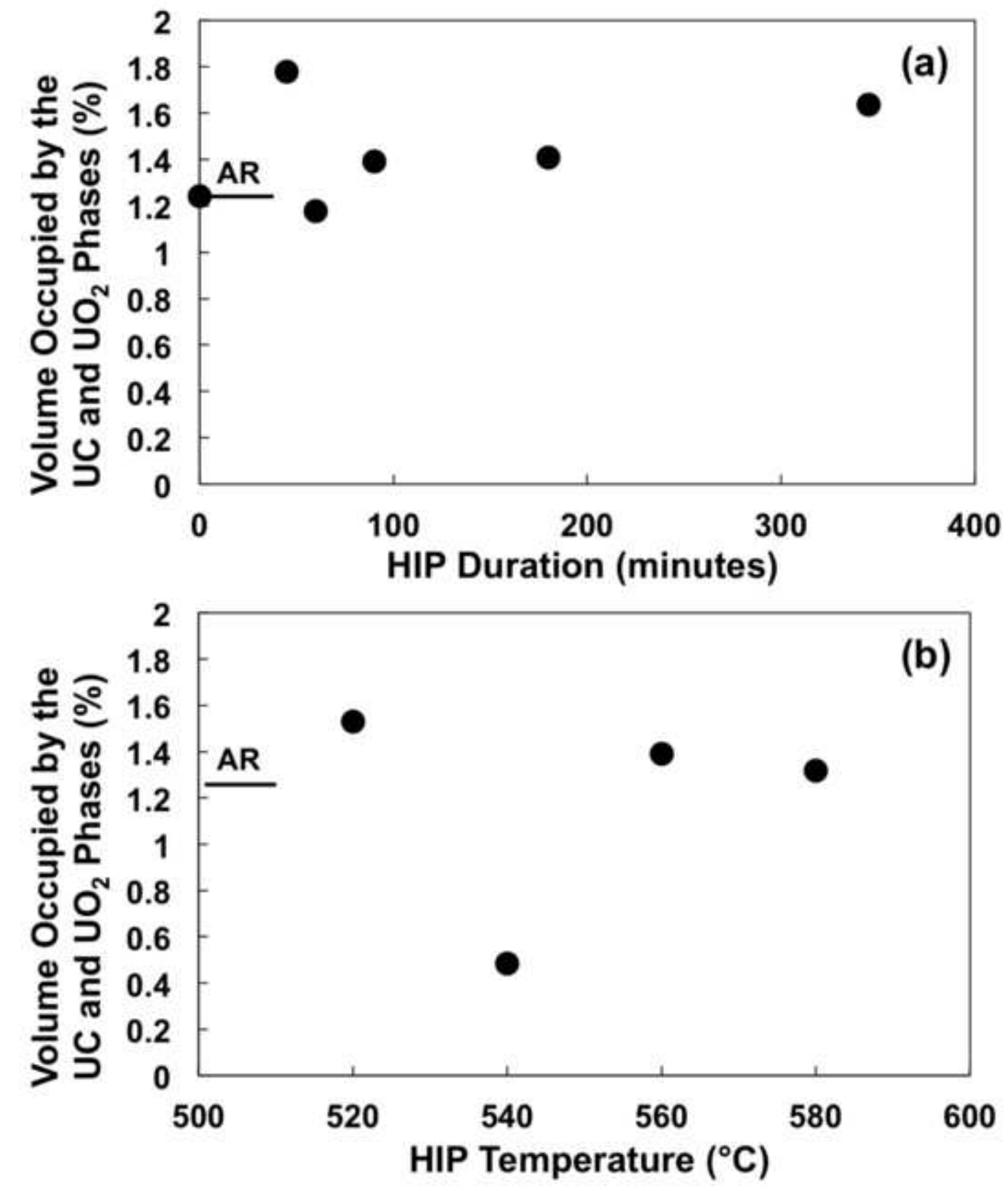


\section{$\mathrm{Zr}$}

U10Mo

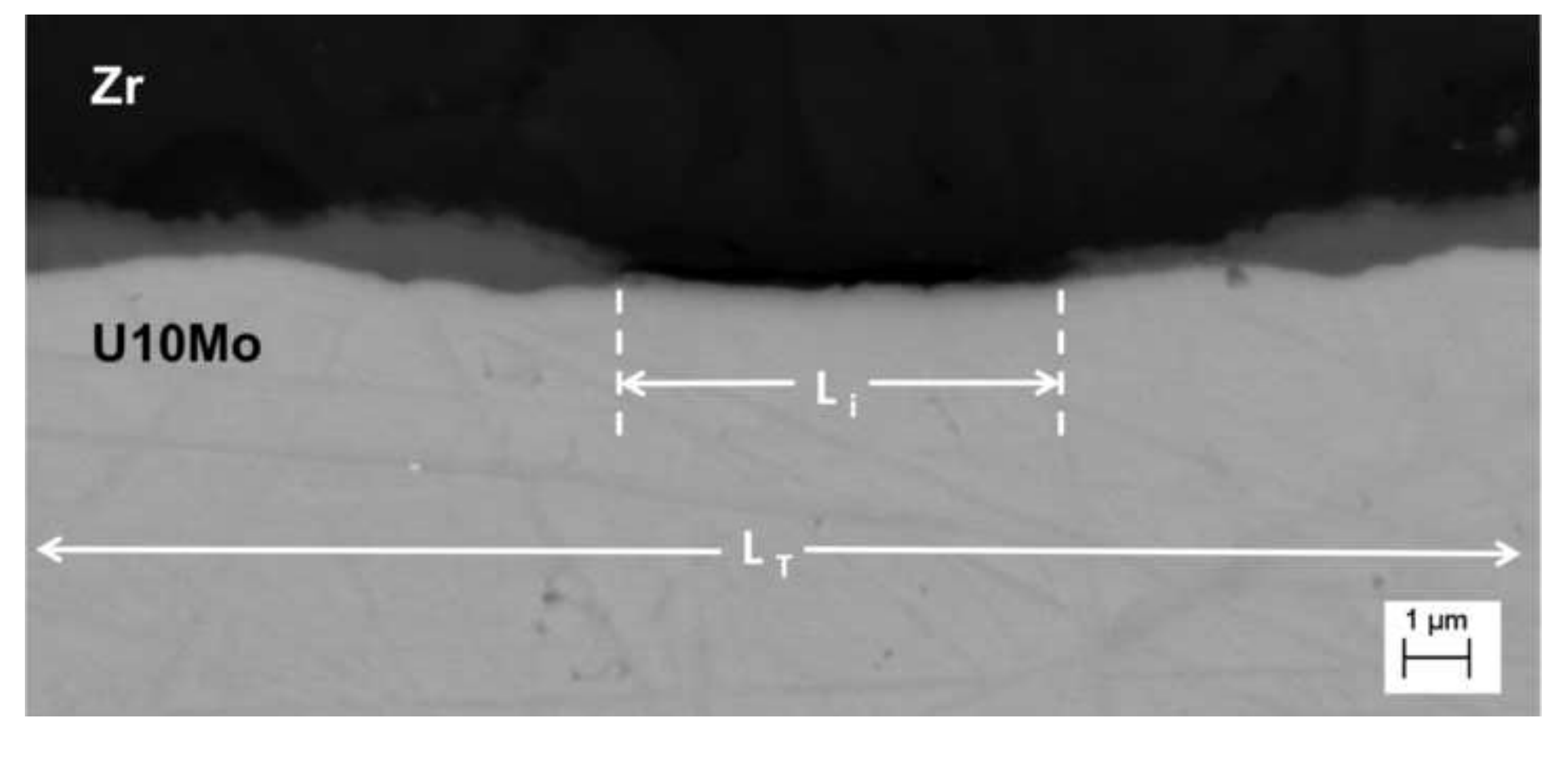

$\mathrm{L}_{\mathrm{T}}$

\section{.}
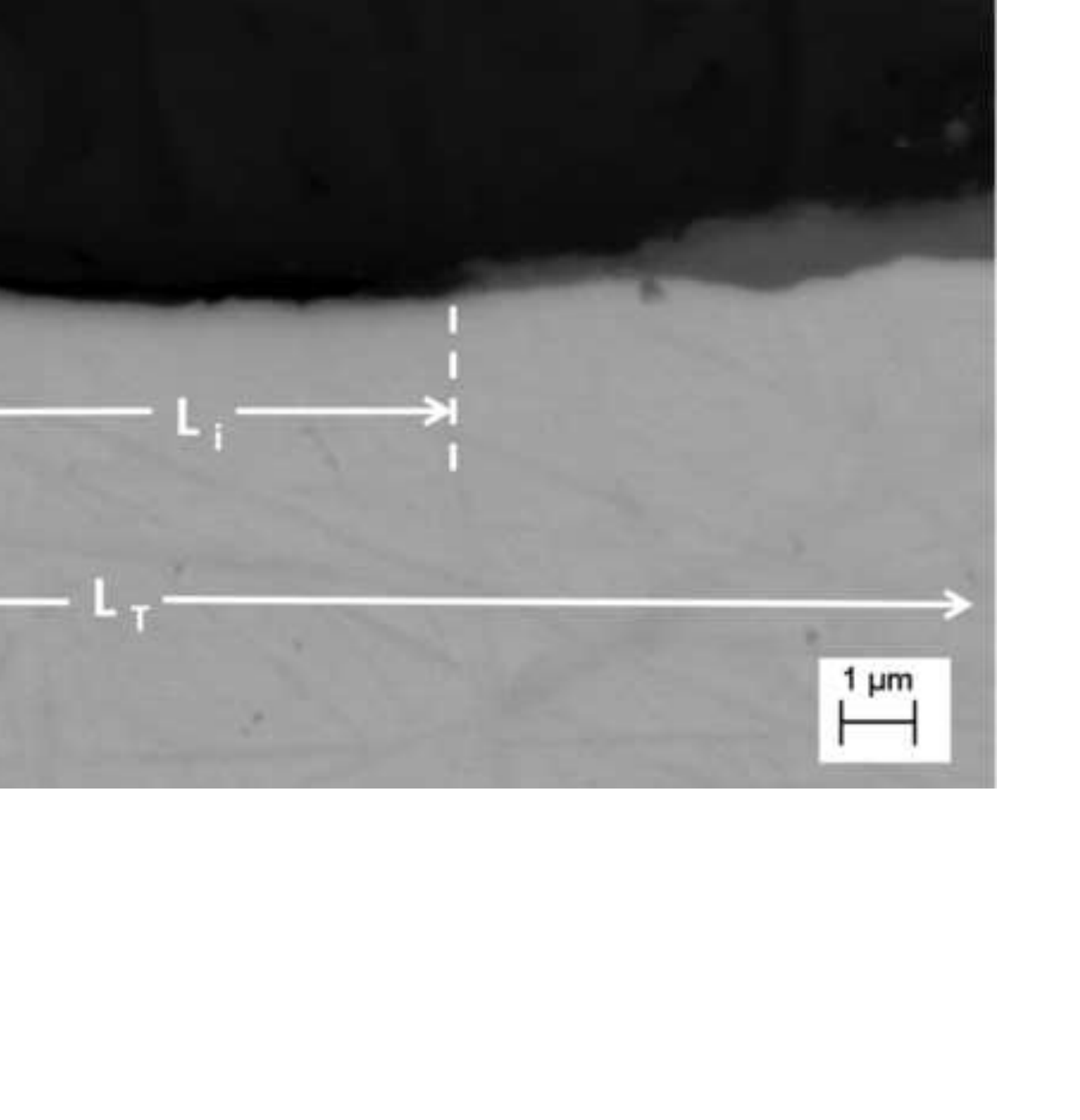
Figure 13
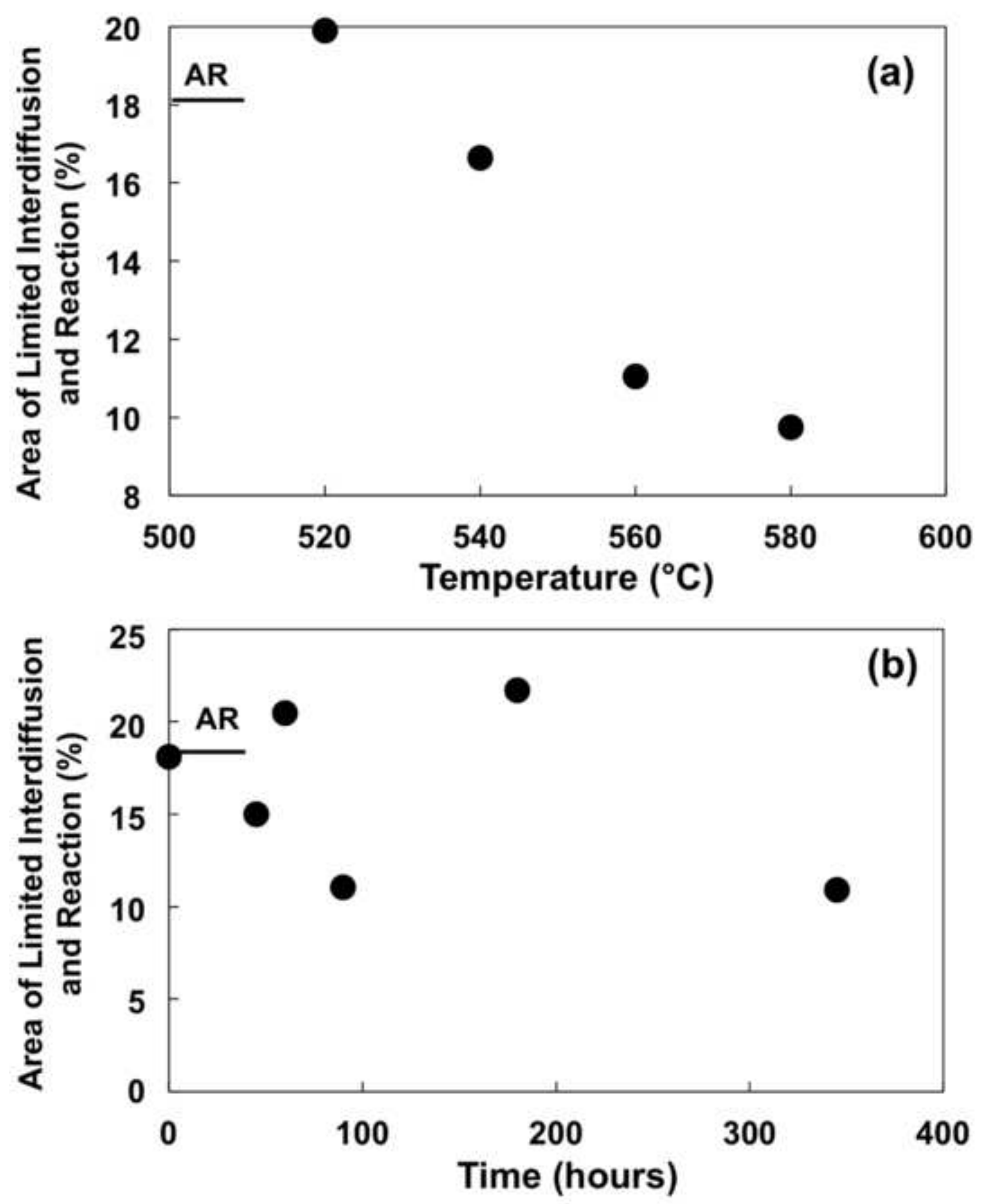